\title{
Application of Diamond Wire Saw Cutting in Demolition of Large Reinforced Concrete Members
}

\author{
Jianhui YI, Tao Liu and Jie Zhou \\ Hunan Aerospace Construction Engineering Co. Ltd., Changsha Hunan China
}

\begin{abstract}
With the rapid development of construction engineering and densely populated of urban buildings, it is impossible to adopt traditional methods for demolition construction due to the constraints of the surrounding environment. This paper combines the demolition engineering practice of the foundation pit support system of Jinyuan International Plaza, expounds the superiority of the application of diamond wire saw cutting in the demolition of large reinforced concrete members, and puts forward the effective construction operation points, which can provide beneficial for similar projects reference.
\end{abstract}

\section{Introduction}

As the development of underground space continues to increase, the foundation pits of the building are also becoming larger and deeper. When the construction is in the intensive and complex surrounding environment, the deep foundation pit support system of "support pile or continuous wall + reinforced concrete internal support" has been used more and more widely. The traditional methods of removing reinforced concrete members (such as ordinary blasting demolition, mechanical demolition, artificial wind blasting, etc.) take a long time, require a lot of labor, and the dust and noise generated during the demolition process are serious environmentally polluted. The traditional methods produce more concrete waste, which is hard to clean up. The vibration generated during the demolition of traditional machinery has a great impact on the new building structure. These reasons make the traditional method cannot met the needs of modern building construction. The problems that need to be solved during construction include reasonable shortening of construction period, ensuring safety, energy saving and environmental protection, and reducing the impact on surrounding buildings. To solved these problems, the method of cutting and dismantling large-scale reinforced concrete members of foundation pit support system with diamond wire saw emerged.

\section{Basic principle}

Diamond wire saw cutting technology was originally used in quarry stone mining. It has also proved to be an ideal method for cutting and removing reinforced concrete. Using the wire sawing principle, the diamond bead is combined into a wire shape by a steel wire rope. And then the diamond rope is driven to rotate by the hydraulic wire sawing machine driving wheel, and at the same time, the diamond rope direction is controlled through the guide wheel, and performs high-speed rotational friction to cut the object body. The body to be cut can be cut and separated with almost no disturbance, and the high-speed rotating diamond rope is cooled with water during the cutting process, and the water carries the grinding debris away. The construction features are as follows:

1) It can cut any orientation and angle at any angle for concrete members of any size.

2) It can be cut in complex, special and difficult environments (such as narrow space, underwater, etc.).

3 ) The size of the cut piece can be controlled at needs, the cutting surface is straight and smooth, and the lifting is convenient.

4) The construction process has low noise, low vibration, less dust and no waste gas pollution.

5) No damage to the parts to be retained, high operational safety, fast cutting speed ( 1 to $1.5 \mathrm{~m}^{2} / \mathrm{h}$ per wire saw cutting machine), no impact on the building structure.

\section{Project Overview}

Jinyuan International Plaza is located in Hengqin New District of Zhuhai City, close to the Hengqin Campus of the University of Macau. The land area is about $6000 \mathrm{~m}^{2}$, and the total construction area is $29568.14 \mathrm{~m}^{2}$. The underground is 4 floors, the ground is 9 floors, the building height is $39.80 \mathrm{~m}$, and the frame is shear wall structure. The shape of the foundation pit is a relatively regular rectangle, the foundation pit is $61.9 \mathrm{~m}$ wide, the length is $72.0 \mathrm{~m}$, the circumference is about $260 \mathrm{~m}$, the depth of the foundation pit (considering the thickness of the bottom plate) is $18.4 \mathrm{~m}$, the part is $20.3 \mathrm{~m}$, and the foundation pit support system is a rotary-excavation pile and three reinforced concrete support beams with a safety 
rating of Class I. The height of the first support beam from the lower structural plate is $2.6 \sim 2.8 \mathrm{~m}$, the height of the second support beam from the lower structural plate is 1.5 $\sim 1.7 \mathrm{~m}$, and the height of the third support beam from the lower structural plate is $0.5 \sim 0.7 \mathrm{~m}$, each support beam has a volume of approximately $1500 \mathrm{~m}^{3}$ and a total of approximately $4,500 \mathrm{~m}^{3}$.

\section{Construction process}

\subsection{Preparation}

Familiar with the design drawings of the reinforced concrete members to be dismantled. Based on the size, engineering quantity and scale of the reinforced concrete members to be dismantled, divide the construction area, select the construction machinery, prepare a special construction plan and implement it after approval, and arrange the water, electricity in advance to meet the rope saw static force cutting demand.

\subsection{Measuring}

According to the lifting performance of the lifting equipment, the rated lifting weight of the forklift, the lifting distance on site, the allowable bearing capacity of the special horse stool, etc., the size of the reinforced concrete block of the cutting section is determined (the density of the reinforced concrete members is calculated according to $2500 \mathrm{~kg} / \mathrm{m}^{3}$ ), and the component cutting points are determined. Use red paint to make a good mark. The segment length of the reinforced concrete block is maximized to the extent necessary to meet the calculation, so as to minimize the cutting effort and achieve the fastest construction speed and maximum economic benefit under the premise of ensuring safety.

\subsection{Supporting system construction}

According to the height of the bottom of the supporting beam and the lower structural plate, the bottom of the reinforced concrete member to be cut is supported (paving) to ensure that the reinforced concrete members of each cutting section can be stable after being cut, without collapse or overturning. As shown in Figure 1-3.

Table 1 support system selection table of support beam bottom

\begin{tabular}{|c|c|c|}
\hline The serial number & $\begin{array}{c}\text { The distance between the bottom of the } \\
\text { supporting beam and the structural plate } \\
\text { surface of the lower layer, } \mathrm{h}(\mathrm{mm})\end{array}$ & Support system selection \\
\hline 1 & $\mathrm{~h} \leq 900$ & Wood support \\
\hline 2 & $900<\mathrm{h} \leq 2000$ & Special horse stool \\
\hline 3 & $2000 \leq \mathrm{h}$ & Clamp and Tube Scaffold \\
\hline
\end{tabular}

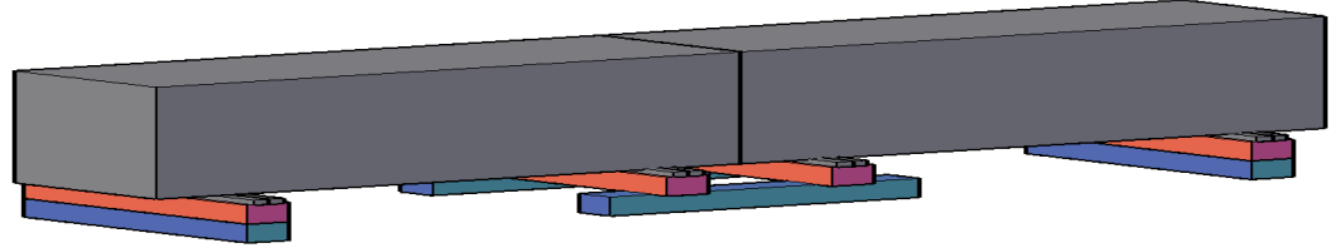

Figure 1 schematic diagram of horse stool construction

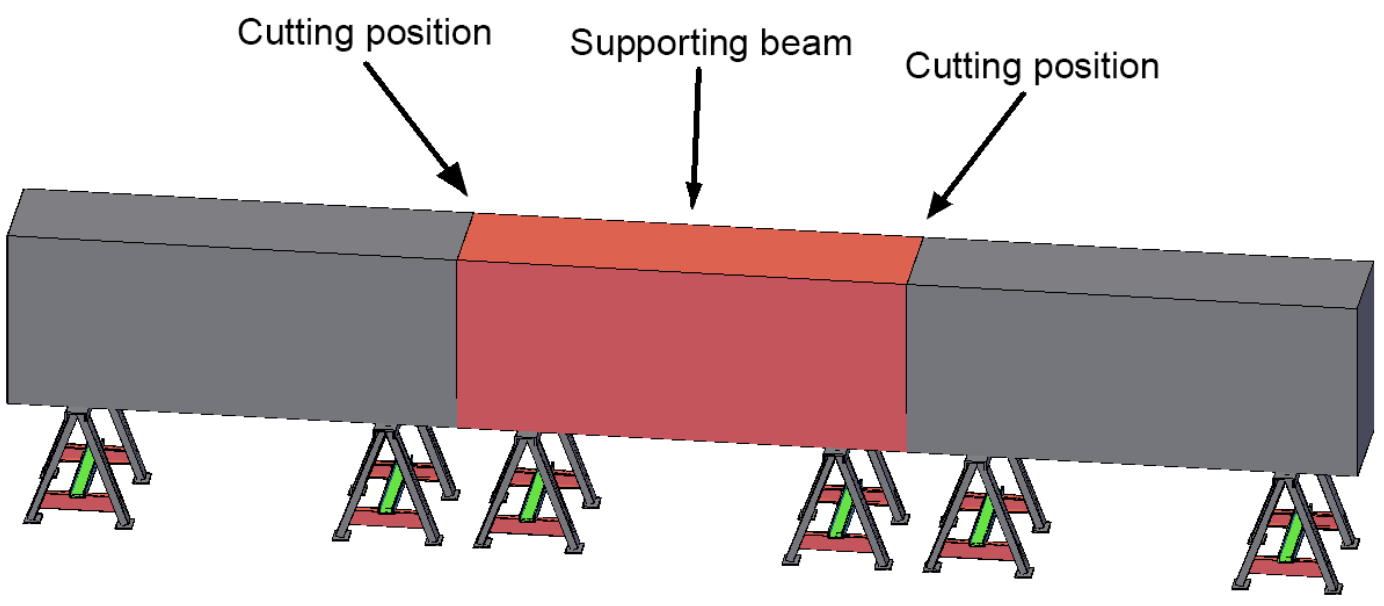

Figure 2 schematic diagram of laying horse stool support 


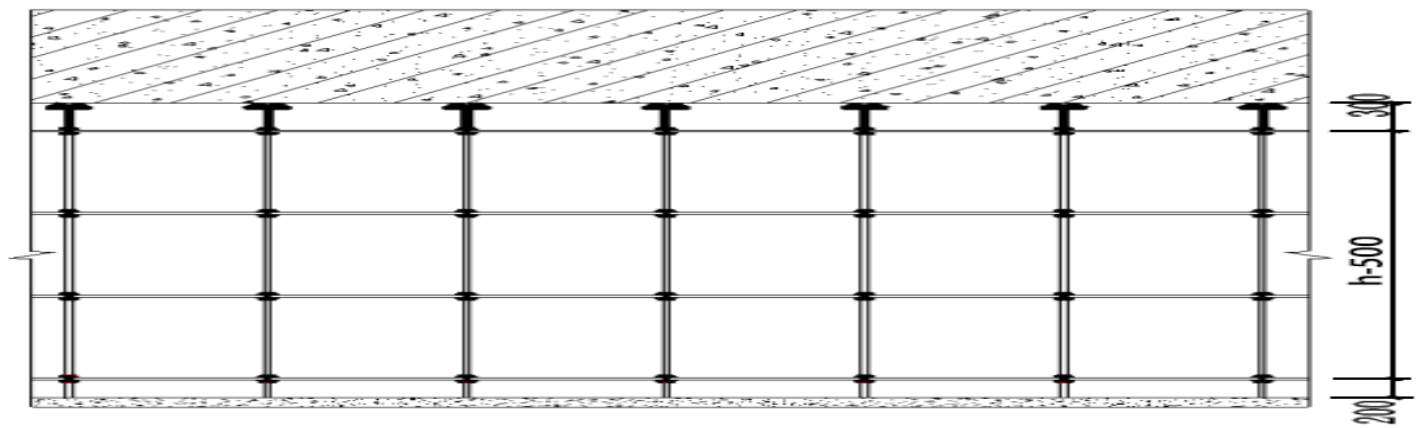

Figure 3 schematic diagram of fastener scaffold support

\subsection{Equipment installation and debugging}

According to the determined cutting form, the diamond rope is placed on the driving wheel. Note that the direction

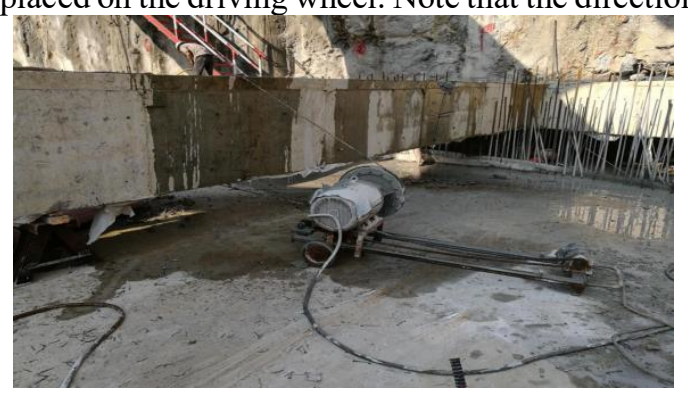

Figure 4 the device is placed on the structural plate

\subsection{Component cutting}

Before the component is cut, based on the cut mark that has been made, the covering layer to be cut is peeled off by the electric shovel to cut out the two side ribs, and the two side ribs are not cut for auxiliary support, thereby reducing stress on the support system. The diamond rope is passed through the two side ribs and fixed on the driving of the rope should be consistent with the driving direction of the driving wheel. After the equipment is installed, the test operation should be carried out to confirm the normal operation of the equipment before cutting as shown in Figure 4-5.

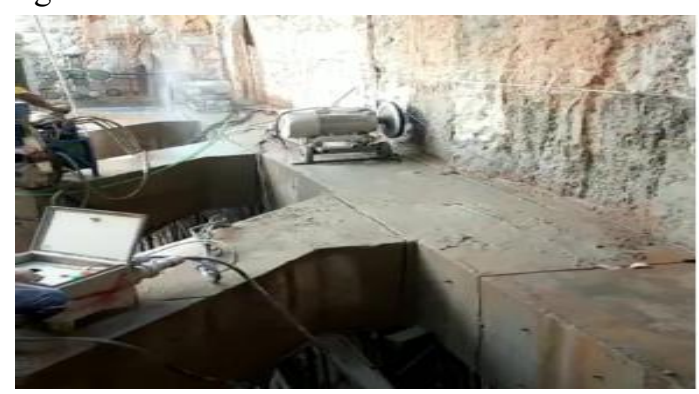

Figure 5 the device is placed on the waist beam

wheel (guide wheel) for cutting work. Because the gap of the cutting surface of the wire saw is small, if the vertical section is cut and the lifting is unbalanced, the component is affected by the resistance of the adjacent component, and there is a hidden danger of lifting safety accident. Therefore, the cutting cross section of the wire rope saw and the cross section of the component should have angle of $5 \%$ to $10 \%$, which is "V" shape after the support beam is cut as shown in Figure 6-8.

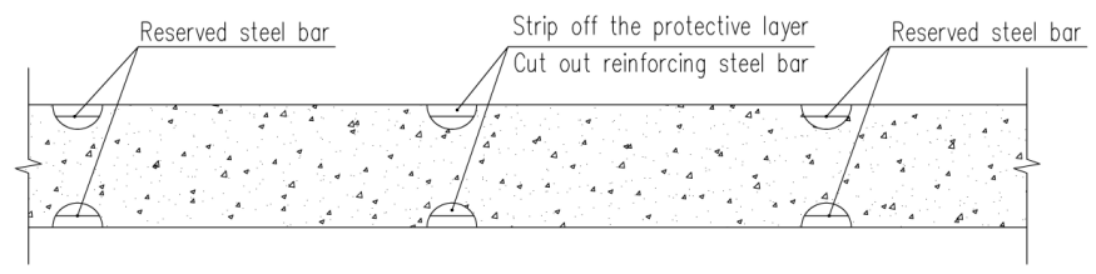

Figure 6 steel reinforcement plan after stripping the protective layer 


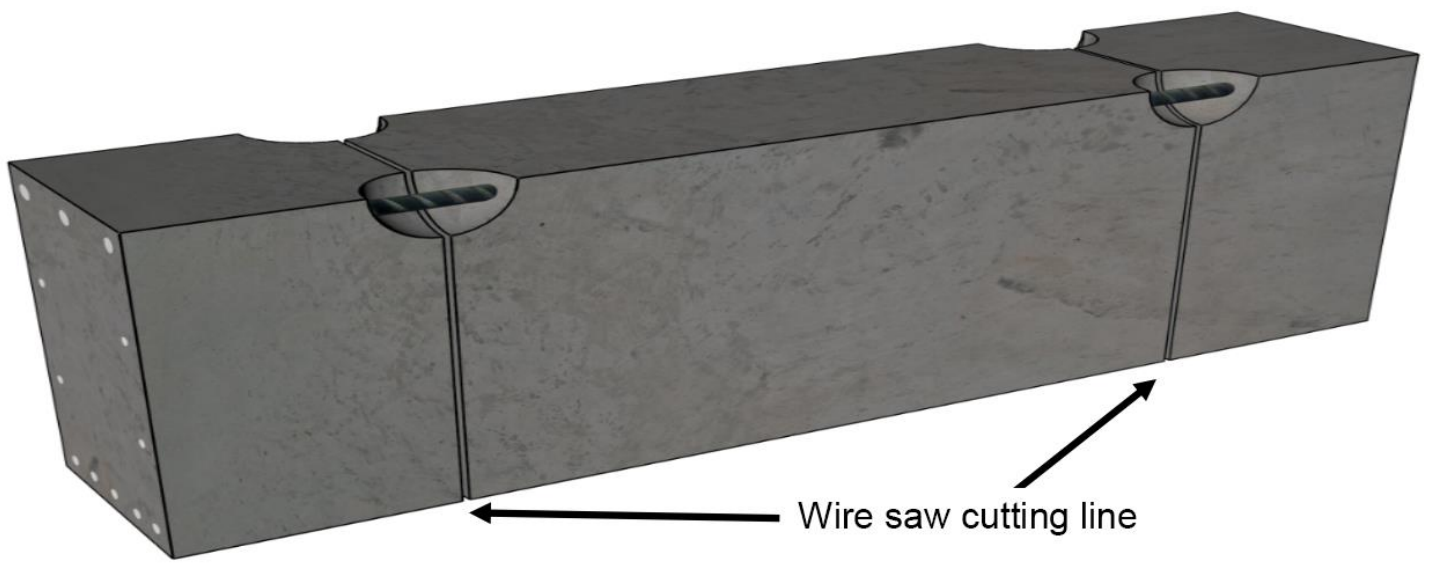

Figure $73 \mathrm{~d}$ drawing of finished cutting components

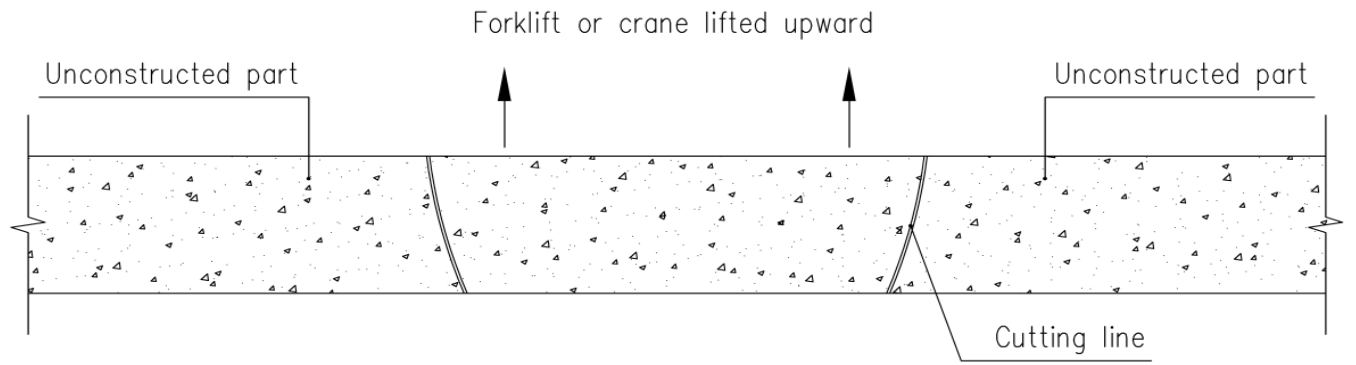

Figure 8 schematic diagram of detailed cutting

\subsection{Forklift with transfer member}

After the whole reinforced concrete member has been cut in sections, the segmented reinforced concrete block is supported from the horse stool by the heavy forklift (10T), and the reinforced concrete block is transferred to the designated stacking area in the foundation pit, and the stacking area needs to be within the coverage of the hoisting equipment. The bottom of the reinforced concrete block in the stacking area shall be provided with skids, and the stacking load shall not exceed the design live load value of this area.

\subsection{Component lifting and shipping}

According to the measured distance of the foundation pit and the weight of the reinforced concrete block after cutting, the hoisting equipment that meets the hoisting requirements is selected, and the reinforced concrete blocks in the designated stacking area are vertically hoisted and loaded, and then Then transfer by dump truck to the off-site rental site stacked and processed as shown in Figure 9-10.

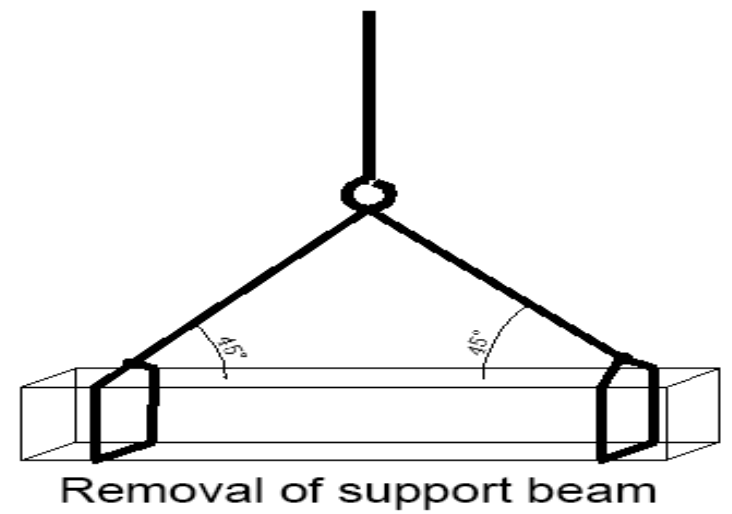

Figure 9 large sample of hoisting binding 


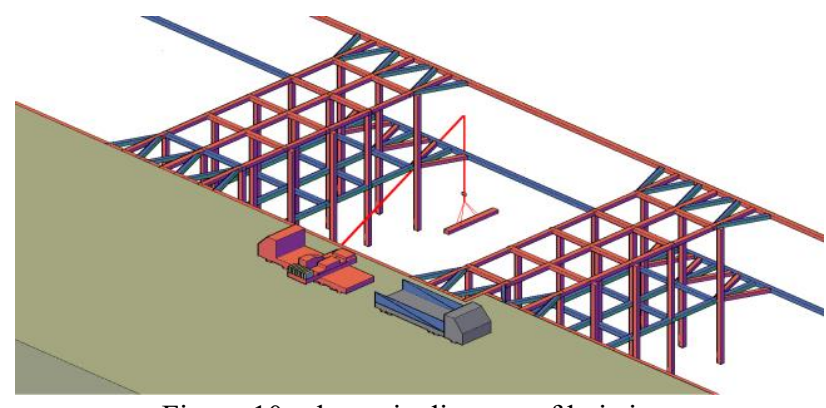

Figure 10 schematic diagram of hoisting

\subsection{Site cleaning}

After the support beam is transported away from the foundation pit, the workers are arranged to clean the completed area in time to ensure that the work is completed.

\section{Conclusion}

Through the application of the diamond wire saw cutting method, the supporting beam demolition project of Jinyuan International Plaza Project in Hengqin New District of Zhuhai has achieved good economic and social effects. The diamond wire saw cutting method has a high degree of mechanization, and this method greatly reduces the removal time of the reinforced concrete members. There are three support systems for the foundation pit support project. The total amount of reinforced concrete demolition works is $4500 \mathrm{~m}^{3}$. It takes at least 60 days to use traditional mechanical or manual demolition. The diamond wire saw cutting method only takes 18 days and the construction period is shortened by 42 days. According to the calculation of the financial department, the project uses diamond wire saw cutting to save about 730,000 yuan compared with traditional machinery or manual demolition. With the continuous development of the construction industry, the requirements for noise reduction, dust reduction, safety and environmental protection, and green construction are getting higher and higher. In the dismantling of large-scale reinforced concrete members, compared with traditionally demolition method (static blasting, artificial blasting etc.), the diamond wire saw cutting method is has unparalleled superiority and has broad application prospects in the cutting and dismantling of large-scale reinforced concrete members.

\section{References}

1. zhou rui, wang shijun. Application of static cutting technology in large frame concrete removal construction $[\mathrm{J}]$. Engineering technology (quoted edition), 2016(11):224-225

2. Yang zhenping, zhao guangmin, Yang jianfeng. Construction method of diamond rope saw cutting concrete.CN201510086218.8

3. construction manual (fifth edition). China building industry press 